\title{
ANENCEPHALIC FETUS WITH CRANIOSPINAL RACHISCHISIS - CASE REPORT
}

\author{
Ayse $\mathrm{KONAC}^{1}$ 四 (i)
}

${ }^{1}$ Gelisim University Health Sciences, Istanbul, Turkey

Received 18 April 2021

Accepted 4 May 2021

Published 31 May 2021

Corresponding Author

Ayse KONAC, ayse.konac1@gmail.

com

DOI $10.29121 /$

granthaalayah.v9.i5.2021.3899

Funding: This research received no specific grant from any funding agency in the public, commercial, or not-for-profit sectors.

Copyright: (C) 2021 The Author(s). This is an open access article distributed under the terms of the Creative Commons Attribution License, which permits unrestricted use, distribution, and reproduction in any medium, provided the original author and source are credited.

OPEN ACCESS

\section{ABSTRACT}

Anencephaly, in which a substantial part of the brain, skull, or scalp is missing, is a lethal neural tube defect (NTD) that occurs during the fourth week of pregnancy after failed cranial neuropore closure. One in every 1,000 births is anencephalic, and newborns with this NTD are not viable or treatable. Associated with anencephaly is rachischisis, or severe incomplete neural tube closure and exposure of the spinal cord. Ultrasonography can quickly diagnose anencephaly. Like other NTDs, nutritional and environmental factors both play a role in the development of anencephaly. Here, we report and discuss an unusual case of a 12-week gestation anencephalic fetus with craniospinal rachischisis and its embryological roots.

In our case, except from the low socio-economic life of the patient, the absence of a predisposing factor that could cause such an anomaly, the abortion being in the first trimester and the occurrence in the first pregnancy of the patient as a result of 5-year infertility made us think that pathology examination of the abortus material is important in complet or incomplete abortions.

Keywords: Anencephaly, Neural Tube Defect, Rachischisis, İncomplet Abortion, First Trimester

\section{INTRODUCTİON}

Anencephaly is a lethal congenital neural tube defect (NTD) that occurs in 1 in every 1,000 births. It is the most prevalent anomaly that affects the central nervous system like other NTDs, anencephaly affects neural and non-neural tissues, including vertebrae, muscles, and skin Gupta (2004); Salder and Lagman's (2012).

The Genesis of Anencephaly is directly related to neur like other NTDs (e.g., Spina Bifida, Encephalocele, Cranioracalvaria), Anencephaly affects neural and non-neural tissues, including vertebrae, muscles, and skinulation, or the process in which the and neurulation is the process in which the neural plate, a neuroectoderm derivative, forms a neural tube that produces the primitive CNS. The lateral edges of the neural 
plate elevate and form neural folds at the end of the third week of pregnancy. In the midline, later neural folds begin to fuse, spreading cranially and caudally to create a neural tunnel. The cranial neuropore closes at or near day 25 of gestation, resulting in a closed tubular structure of the primordial CNS and caudal neuropore by day 28. The neural tube's cranial neuropore then goes on to form the hippocampus, and the caudal neuropore grows into the spinal cord. NTDs in the third and fourth weeks of development typically arise from abnormal closures of the neural folds Moore and Persud (2009); Salder and Lagman's (2012).

Anencephaly specifically is caused during the fourth week of pregnancy after the failed closure of the cranial neuropore (1). As a consequence, the main part of the brain is abnormal, and the development of the calvaria is faulty. Most of the nervous tissue is then subject to degeneration or atrophy by exposure or extrusion from the skull. While this NTD is commonly referred to as anencephaly ("without brain tissue"), meroanencephaly ("partial lack of brain tissue") might be a better word for some iterations of this phenomenon, as rudimentary neural tissue can still be present (2). Anencephaly is also associated with acrania (absence of the calvaria or skullcap) and rachischisis, which is the full exposure or extensive deficient closure of the spinal cord. As a consequence of defective notochosis induction, rachischisis affects the axial structures as well Moore and Persud (2009); Salder and Lagman's (2012). NTDs are strongly suspected in utero when maternal serum and amniotic fluid show a high level of the alpha-fetoprotein (AFP) (4). This report outlines one such case of anencephaly with rachischisis.

\section{CASE REPORT}

A 26-year-old woman at gravida 1 was admitted to the Istanbul Training and Research Hospital for surgical pregnancy termination after the fetus was diagnosed with craniospinal rachischisis anencephaly. The patient had been married 5 years in a non-consanguineous marriage and smoked 3-4 cigarettes a day, but did not drink alcohol. The patient had endured 1 year of male factor infertility complaints and became pregnant as a result of infertility treatment. She also fell into a low socioeconomic status.

The patient was at 12 weeks gestation according to the date of her last menstrual cycle. With natural discharge, her menstrual cycle was typical prior to pregnancy. Hypertension, gestational diabetes mellitus, diabetes mellitus, and cardiac and renal disease had not emerged in her brief pregnancy history. Since the beginning of her pregnancy, the patient had been taking iron and folic acid pills. She had no family history of NTDs, and she did not report any drug use. Further, the patient was moderately developed upon inspection, measured $161 \mathrm{~cm}$ tall, and weighed $56 \mathrm{~kg}$. Her heartbeat, pulse, and blood pressure were natural, with a result of $109 \mathrm{mg} / \mathrm{dl}$ for spontaneous blood glucose. Tests for urinaryenfection, HIV, and HbSAg were negative. 


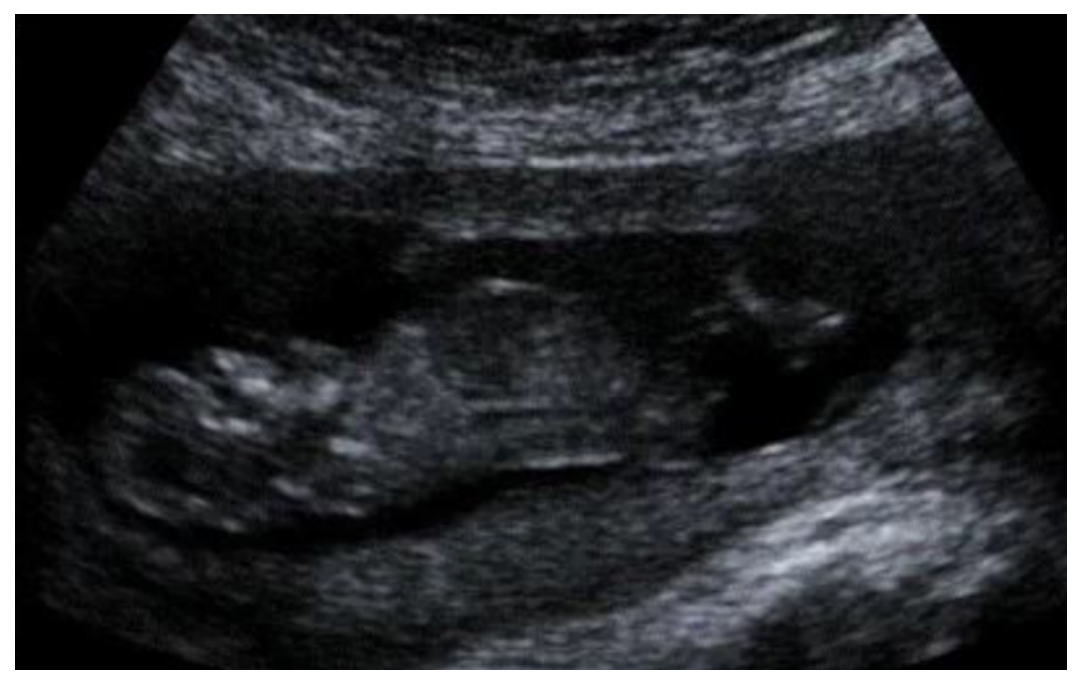

Figure 1 Acrania fetus first trimester

Figure 2 Material of Abortion

The patient came to the clinic with complaints of excessive bleeding and abdominal pain. Upon examination, abortus materials in the vagina and residual pregnancy materials in the endometrium were found by Ultrasonography and the patient was diagnosed with incomplete abortion. She was hospitalized on the same day and under general anesthesia revision curettage made on the same day. After curettage, both the vaginal and endometrium material were sent for pathological testing.

The pathology results reported a fetus with anomaly compatible with 12 weeks of gestation. The findings signaled anencephaly, rachischisis (craniospinal), as well 
as pulmonary extra-lobar sequestration (localized in the abdomen) and gastroschis. There were no anomalies in the other internal organs.

\section{DísCUSSION}

The prevalence of anencephaly varies according to region, race, gender, and environmental factors. Per a population-based study from India, every 2.5 in 1,000 births had anencephaly, with NTDs in general ranging from every 6.57 to 8.21 in 1,000 births Cherian et al. (2005). In another prospective study of 3,500 consecutive births from southern India, 11.4/1,000 births with NTDs occurred, with 5.1/1,000 births attributable to craniospinal rachischisis anencephaly. In cases where there was a history of NTDs or consanguineous marriage, there was an increased probability of NTD occurrence Kulkarni et al. (1989). Overall, China had the highest incidence of live births with NTDs $(11.39 / 1,000)$, while the lowest incidence of live births with NTDs was recorded in the U.S.A. (1/1,000) Detrait et al. (2005); Li et al. (2006). Large numbers of congenital malformations and genetic abnormalities are also one of the factors of child mortality and morbidity in developing countries. For instance, one survey carried out on 94,640 newborns to clarify the incidence of malformations noted a $2.03 \%$ rate of malformed babies and NTDs, with musculoskeletal disabilities the most prevalent Verma (2000).

It is thought that NTDs arise from complex interactions between environmental and genetic variables. Such environmental variables include age, periconceptual infection, recreational drug use, caffeine, smoking, and alcohol consumption Detrait et al. (2005); Moore and Persud (2009); Verma (2000). Extensive clinical and epidemiological research has also shown that the incidence of NTDs increases with inadequate maternal nutrition, primarily low folic acid levels, and low socioeconomic status.

For the neural tube to properly develop, other micronutrients such as vitamins B6 and B12 and minerals such as zinc are also necessary, though holotranscobalamin helps monitor vitamin B12 specifically as a sensitive predictor Ray et al. (2007). Further, NTDs can form by taking certain medications, such as valproic acid and anticonvulsants, and being exposed to high levels of vitamin A Berry et al. (1999); Blancquaert et al. (2010); Ray et al. (2007).

As for genetic variables, research implies that genes involved especially in the metabolism of folate are significant in generating NTDs. For instance, the methylenetetrahydrofolate reductase mutation is responsible for folate-related NTDs Put et al. (1998). However, during the periconceptual period, administering food with folic acid (400 $\mu \mathrm{g})$ and synthetic vitamin B12 decreased the risk of NTDs in the U.S.A. by 50-70\% Houk et al. (1992); Put et al. (1998).

In conclusion, assessing the Alpha Feto Protein level and early USG in at-risk pregnancies can assist in the early detection of NTDs. Genetic counseling is also useful for planning future pregnancies; as there are no viable curative modalities, though, 
therapeutic emphasis largely falls on preventive step Houk et al. (1992). Studies have shown that by taking folic acid supplements daily during pregnancy, the frequency of NTDs can be decreased. Because most pregnancies are unplanned, even the administration of multivitamins containing $400 \mu \mathrm{g}$ of folic acid to all women of childbearing age should be suggested to decrease the chance of NTD genesis Tuncbilek (2004).

Neural tube defects are among the most severe congenital anomalies in Turkey and epidemiological findings show that the prevalence varies according to regional and demographical characteristics. According to the studies conducted in various cities of Turkey, NTD incidence varies between 3 and 5.8 per thousand Tuncbilek (2004).

Although there is no predisposing factor for fetal anomaly especially in infertile cases, if there is abortion, even if the gestational week is small, talking to the patient and informing her and sending the curettage material to pathology examination would be helpful in detecting unexpected anomalies. In our case, there was no history of giving birth with other anomalies in the family of the patient and her husband.

\section{REFERENCES}

Berry, R. J., Li, Z., Erickson, J. D., Li, S., Moore, C. A., Wang, H., \& Mulinare, J. (1999). Prevention of neural-tube defects with folic acid in China. Engl J Med.

Blancquaert, D., Storozhenko, S., Loizeau, K., Steur, H. D., Brouwer, V. D., Viaene, J., Ravanel, S., Rébeillé, F., Lambert, W., \& Straeten, D. V. D. (2010). Folates and Folic Acid: From Fundamental Research Toward Sustainable Health. Critical Reviews in Plant Sciences, 29(1), 14-35. Retrieved from https://dx.doi.org/10.1080/07352680903436283 10.1080/ 07352680903436283

Cherian, A., Seena, S., Bullock, R. K., \& Antony, A. C. (2005). Incidence of neural tube defects in the least-developed area of India: a population-based study. The Lancet, 366(9489), 930-931. Retrieved from https://dx.doi.org/10.1016/s0140-6736(05)67319-9 10 .1016/s0140-6736(05)67319-9

Detrait, E. R., George, T. M., Etchevers, H. C., Gilbert, J. R., Vekemans, M., \& Speer, M. C. (2005). Human neural tube defects: Developmental biology, epidemiology, and genetics. Neurotoxicology and Teratology, 27(3), 515-524. Retrieved from https://dx.doi.org/10 .1016/j.ntt.2004.12.007 10.1016/j.ntt.2004.12.007

Gupta, H. (2004). Neural tube defects and folic acid. Indian Pediatr, 41577586-41577586.

Houk, V. N., Oakley, G. P., Erickson, J. D., Mulinare, J., \& James, L. M. (1992). Recommendations for the Use of Folic Acid to Reduce the Number of Cases of Spina Bifida and Other Neural Tube Defects. Atlanta: Centers for Disease Control, 26, 23-34.

Kulkarni, M. L., Mathew, M. A., \& Reddy, V. (1989). The range of neural tube defects in southern India. Archives of Disease in Childhood, 64(2), 201-204. Retrieved from https://dx.doi .org/10.1136/adc.64.2.201 10.1136/adc.64.2.201

Li, Z., Ren, A., Zhang, L., Ye, R., Li, S., \& Zheng, J. (2006). Extremely high prevalence of neural tube defects in a 4-county area in Shanxi Province China. BDR: A Clinical and Molecular Teratology, 4237240-4237240.

Martinelli, M., Scapoli, L., Pezzetti, F., Carinci, F., Carinci, P., Stabellini, G., Bisceglia, L., Gom- 
bos, F., \& Tognon, M. (2001). C677T variant form at the MTHFR gene and CL/P: A risk factor for mothers? American Journal of Medical Genetics, 98(4), 357-360. Retrieved from https://dx.doi.org/10.1002/1096-8628(20010201)98:4<357::aid-ajmg1108>3 .0.co;2-f 10.1002/1096-8628(20010201)98:4<357::aid-ajmg1108>3.0.co;2-f

Moore, K. L., \& Persud, T. (2009). The Developing Human - Clinically Oriented Embriology, 8th edn. Sauders, 62-75.

Put, N. V. D., Gabrels, F., Stevens, E., \& Frans, J. M. (1998). A second common mutation in the methylenetetrahydrofolate reductase gene: an additional risk factor for neural-tube defects? Am J Human Genet, 510441051-510441051.

Ray, J. G., Wyatt, P. R., Thompson, M. D., Vermeulen, M. J., Meier, C., Wong, P.-Y., Farrell, S. A., \& Cole, D. E. C. (2007). Vitamin B12 and the Risk of Neural Tube Defects in a FolicAcid-Fortified Population. Epidemiology, 18(3), 362-366. Retrieved from https://dx .doi.org/10.1097/01.ede.0000257063.77411.e9 10.1097/01.ede.0000257063.77411 .89

Salder, T. W., \& Lagman's. (2012). Medical Embryology, 63(70), 296-297.

Tuncbilek, E. (2004). neural tube defect prevalence and high in Turkey what can be done to prevent. Child Health and Diseases Journal, 47, 79-84.

Verma, I. C. (2000). Burden of genetic disorders in india. The Indian Journal of Pediatrics, 67(12), 893-898. Retrieved from https://dx.doi.org/10.1007/bf02723953 10.1007/ bf02723953 